\title{
Keanekaragaman Hayati Fauna di Sungai Surgi Mufti Kecamatan Banjarmasin Utara
}

\section{Fauna Biodiversity in the Surgi Mufti River in the North Banjarmasin District}

\author{
Syahbudin ${ }^{1, *}$, Fujianor Maulana ${ }^{1}$ \\ ${ }^{1}$ STKIP PGRI Banjarmasin, Jl. Adam Sultan Komplex H. Iyus No. 18, Banjarmasin, Sungai Jingah, Banjarmasin Utara, \\ Kalimantan Selatan \\ * Email Korespondensi: geneticstudio@gmail.com \\ doi: https://doi.org/10.29405/j.bes/22135-1392484 \\ Received: 4 November 2018 | Accepted: 12 Desember 2018 | Published: 31 Desember 2018
}

\begin{abstract}
Abstrak
Background: Penelitian ini bertujuan untuk mengetahui keanekaragaman hayati di sungai Surgi Mufti Kecamatan Banjarmasin Utara. Metode: Metode yang digunakan adalah metode titik, sweeping, dan tracking. Penelitian ini ilakukan pada pagi, siang, sore, dan malam hari di bulan januari-maret 2018. Analisis data menggunakan Indeks Keanekaragaman Shannon-Weiner's (H'). Hasil: Hasil penelitian yang telah dilakukan, ditemukan 45 jenis hewan, yaitu: 12 jenis capung, 9 jenis herpetofauna, 9 jenis burung, 8 jenis kupu-kupu, dan 7 jenis ikan. Keanekaramgan tertinggi pada kelompok capung dengan nilai $\mathrm{H}^{\prime}=2,35$, sedangkan yang terendah pada kelompok ikan dengan nilai $\mathrm{H}^{`}=1,76$.
\end{abstract}

Kata kunci: Keanekaragaman hayati; Fauna; Sungai Surgi Mufti

\section{Abstract}

Background: This study aims to determine the biodiversity of the Surgi Mufti river in the North Banjarmasin District. Method: The method used is the point, sweeping method, and tracking. Performed in the morning, afternoon, evening in January-March 2018. Analysis of data using the Shannon-Weiner Diversity Index ( $\left.H^{\prime}\right)$. Result: The results of research that has been done, found 45 species of animals, namely: 12 types of dragonflies, 9 types of herpetofauna, 9 species of birds, 8 types of butterflies, and 7 species of fish. The highest diversity in the dragonfly group with the value of $H=2.35$, while the lowest in the group of fish with the value of $H=1.76$.

Keywords: Biodiversity; Fauna; Mufti river

Cara Sitasi: Syahbudin dan Maulana, F. 2018. Keanekaragaman Hayati Fauna di Sungai Surgi Mufti

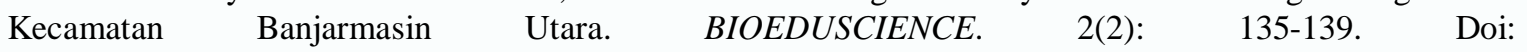
https://doi.org/10.29405/j.bes/22135-1392484

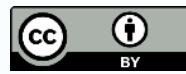

(C) 2018 Oleh authors. Lisensi Bioeduscience, Uhamka, Jakarta. Artikel ini bersifat open access yang didistribusikan di bawah syarat dan ketentuan Creative Commons Attribution (CC BY) license. (http://creativecommons.org/licenses/by/4.0/).

\section{PENDAHULUAN}

Banjarmasin yang dikenal sebagai kota "seribu sungai", terdiri dari 3 sungai kategori besar (lebar > 50 meter); 45 sungai kategori sedang (lebar berkisar 15-50 meter); dan 54 sungai kategori kecil (lebar $<15$ meter). Sungai Barito,
Martapura, dan Alalak tergolong dalam sungai besar. Sedangkan sungai Surgi Mufti (dulunya bernama Sungai Jingah) termasuk dalam kategori sungai kecil (Pemko Banjarmasin, 2015).

Sungai Surgi Mufti (dulunya bernama Sungai Jingah) adalah sungai yang terletak di Kelurahan Sungai Jingah Kecamatan Banjarmasin 
Utara Kota Banjarmasin. Panjang sungai 1.578 meter dengan lebar 14 meter. Sungai ini merupakan anak dari Sungai Martapura.

Seiring tumbuh dan berkembangnya populasi masyarakat, keberadaan sungai mulai kurang diperhatikan lagi. Sungai sering dianggap sebagai ruang kosong yang tidak bermanfaat sehingga menjadi pembuangan sampah dan limbah. Menurut Khaliq (2015) aliran air limbah existing pada Kelurahan Kelayan Luar Kota Banjarmasin yang berpenduduk 4.801 jiwa dan luas wilayahnya 22.05 ha adalah 6,6680556 1/detik (tahun 2014), sedangkan untuk debit aliran air limbah pada 10 tahun ke depan adalah 7,2625 1/detik (tahun 2024). Ancaman ini bisa terjadi juga di sungai Surgi Mufti yang berada di kota Banjarmasin Utara. Hal ini dapat dilihat dari indeks sanitasi Sungai Surgi Mufti yang masuk pada kategori klaster tiga dengan resiko tinggi (Banjarmasin, 2012)

Seperti yang disebutkan Maryono (2005), Profil melintang Sungai dapat dibagi menjadi beberapa zona misalnya zona Aquatik, zona amfibi, dan zona kering. Zona tersebut sebenarnya merupakan daerah yang dibedakan berdasar frekuensi penggenangan. Zona Aquatik adalah zona penggunaan relatif tertinggi, sebaliknya zona kering pengguna penggenangan nya relatif jarang. Hal ini terdapat pada zona-zona di Sungai Surgi Mufti. Perbedaan zona ini juga menjadikan keragaman vegetasi..

Dari hal di atas, perlu adanya suatu penelitian jenis fauna apa saja yang menghuni dari zona-zona tersebut. Informasi ini penting untuk menyadarkan warga bahwa ada kehidupan lain di sekitar mereka yang perlu diperhatikan.

\section{MATERI DAN METODE}

Penelitian ini merupakan penelitian deskriptif kuantitatif menggunakan metode titik dan Sweeping. Dilakukan selama 3 bulan dari bulan Januari s.d. maret 2018. Metode titik digunakan untuk mengambil sampel dari jenis ikan yaitu dengan meletakan jaring ikan dan jebakan di titik-titik tertentu. Sedangkan untuk kupu-kupu, capung, burung, dan herpetofauna, menggunakan metode sweeping dan tracking.

Populasi dalam penelitian ini adalah keseluruhan fauna yang didapat dari jenis capung, herpetofauna, burung, kupu-kupu, dan ikan. Alat yang digunakan dalam penelitian ini berupa jaring serangga, Alat tangkap ikan, teropong, dan kamera.

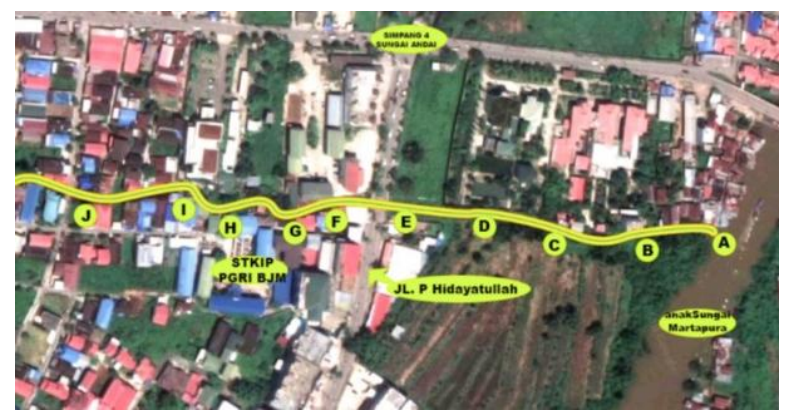

Gambar 1. Lokasi pengambilan data di Sungai Surgi Mufti Kecamatan Banjarmasin Utara

\section{Analisis Data}

Ada dua analisis keanekaragaman hayati yang dilakukan, yaitu:

a) Mengetahui jenis fauna apa saja yang tertangkap. Untuk Identifikasi menggunakan buku panduan: Serangga: Butterfly World, Paul Smart Fres (1989) dan Naga Terbang Wendit, Wahyu SR (2013). Herpetofauna: Frogsofborneo.org dan Panduan Bergambar Identifikasi Amfibi Jawa Barat, Mirza D. Kusrini (2013). Burung: Panduan Lapangan Burung Sumatera, Jawa, Bali, dan Kalimantan, Mac Kinnon (2010). Ikan: Taksonomi dan Kunci Identifikasi Ikan, Saanin (1984)

b) Analisis keanekaragaman hayati menggunakan rumus Shannon-Winner $\left(\mathrm{H}^{\prime}\right)$ yaitu :

$$
H^{\prime}=\sum p_{i} \ln p_{i} \quad \text { dimana }: \quad p i=\frac{n_{i}}{N_{i}}
$$

Keterangan :

$p_{i}=$ Kemelimpahan proporsional dan jenis ke-i

$n_{i}=$ Jumlah individu Ke-i

$N_{i}=$ Jumlah total individu jenis dalam komunitas

$H^{\prime}=$ Nilai indeks Keanekaragaman

(Magurran, A. E., \& McGaill, B. J., 2011) 
HASIL

\section{Fauna yang ditemukan}

Hasil penelitian yang dapat kita lihat pada Tabel 1. Ditemukan kelompok ikan sebanyak 7 spesies, capung 12 spesies, kupu-kupu 8 spesies, herpetofauna 9 spesies, dan burung 8 spesies.

Tabel 1. Daftar spesies yang ditemukan

\begin{tabular}{|c|c|c|c|}
\hline Fauna & No. & Spesies & Jml \\
\hline \multirow{7}{*}{ Ikan } & 1 & Aplocheilus panchax & 7 \\
\hline & 2 & Dermogenys pusilla & 6 \\
\hline & 3 & Trichogaster trichopterus & 5 \\
\hline & 4 & Channa striata & 2 \\
\hline & 5 & Anabas testudineus & 2 \\
\hline & 6 & Osteochilus melanopleurus & 2 \\
\hline & 7 & Monopterus albus & 1 \\
\hline \multirow{12}{*}{ Capung } & 1 & Orthtrum sabina & 5 \\
\hline & 2 & Agriocnemis pygmaea & 4 \\
\hline & 3 & thollymis tilarga & 3 \\
\hline & 4 & Rhyothemis phylis & 3 \\
\hline & 5 & Ceriagrion cerinorubellum & 3 \\
\hline & 6 & Brachythemis contaminata & 2 \\
\hline & 7 & Neurothemis fluctuans & 2 \\
\hline & 8 & Pseudagrion microcephallum & 2 \\
\hline & 9 & Urothemis signata & 1 \\
\hline & 10 & Ictinogomphus decoratus & 1 \\
\hline & 11 & Agriocnemis minima & 1 \\
\hline & 12 & Ischnura senegalensis & 1 \\
\hline \multirow{8}{*}{$\begin{array}{l}\text { Kupu- } \\
\text { kupu }\end{array}$} & 1 & Hipolimnas bolina & 2 \\
\hline & 2 & Papilio memnon & 2 \\
\hline & 3 & Eurema hecabe & 2 \\
\hline & 4 & eurema blanda & 1 \\
\hline & 5 & Dunonia atlites & 1 \\
\hline & 6 & Catopsilia pomona & 1 \\
\hline & 7 & Euploea crameri & 1 \\
\hline & 8 & Neptis hylas & 1 \\
\hline \multirow{6}{*}{$\begin{array}{l}\text { Herpeto } \\
\text { fauna }\end{array}$} & 1 & Bufo asper & 4 \\
\hline & 2 & Fejervarya cancrivora & 3 \\
\hline & 3 & Rana chalconota & 3 \\
\hline & 4 & Varanus salvator & 2 \\
\hline & 5 & Mabuya multifasciata & 2 \\
\hline & 6 & Calloselasma rhodostoma & 1 \\
\hline
\end{tabular}

\begin{tabular}{cclc}
\hline Fauna & No. & \multicolumn{1}{c}{ Spesies } & Jml \\
\hline & 7 & Bronchocela jubata & 1 \\
& 8 & Dryophis prasinus & 1 \\
& 9 & Cosymbotus platyurus & 1 \\
\hline \multirow{6}{*}{ Burung } & 1 & Lonchura fuscans & 8 \\
& 2 & Passer Montanus & 6 \\
& 3 & Hirundo tahitica & 5 \\
& 4 & Collocalia linchi & 4 \\
& 5 & Pycnonotus aurigaster & 2 \\
& 7 & Anthreptes malacensis & 2 \\
& 8 & Haliastur indus & 2 \\
& 9 & Alcedo meninting & 1 \\
\hline
\end{tabular}

\section{Keanekaragaman Hayati}

Berdasarkan perhitungan keaneka-ragaman Shannon-Winner (H'), secara umum, keanekaragaman Fauna keseluruhan yang diamati cukup tinggi yaitu 3,59. Walaupun jika di pisah berdasar kelompok fauna, semua kelompok masuk pada kategori sedang $\left(1 \leq \mathrm{H}^{\prime} \leq 3\right)$, dapat dilihat pada gambar 4 berikut.

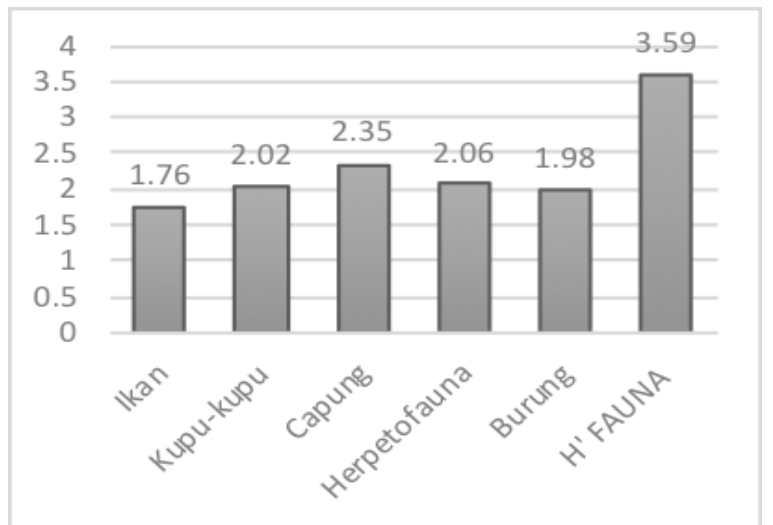

Gambar 4. Perbandingan keanekaragaman Shannon-Winner (H') pada beberapa fauna yang ditemukan.

\section{PEMIBAHASAN}

\section{Fauna yang ditemukan}

Berdasarkan Tabel 1 di atas, pada kelompok fauna ikan, Spesies Aplocheilus panchax (kepala timah) paling banyak ditemukan di sekitar sungai Surgi Mufti. Menurut Weber, M. and L.F. de Beaufort. (1922) spesies ini mempunyai kemampuan adaptasi yang tinggi, kepala timah ditemukan hidup di pelbagai perairan tawar 
hingga payau. Ikan ini biasanya menghuni air yang menggenang dan ternaungi. Aplocheilus panchax juga memangsa aneka serangga dan tempayaknya; sejak lama telah dikenal sebagai pemangsa. Kondisi sungai Surgi Mufti cocok dengan habitat yang disukai Aplocheilus panchax, karena air sungai mengalir pelan dan banyak naungan dari vegetasi di sisi sungai. Selain itu, berbagai serangga air dan tempayaknya misal dari nimfa capung yang banyak di sungai menjadi sumber makanan bagi ikan tersebut. Menurut Kottelat dkk. (1996), ikan kepala timah tergolong spesies ikan yang berenang secara berkelompok dan memilih-milih jenis perairan sehingga keterdapatannya terbatas atau hanya pada tempattempat tertentu.

Spesies ikan lain yang juga banya ditemukan adalah ikan julung-julung (Dermogenys pusilla). Ikan ini herbivora ini makan berbagai jenis algae, partikel-partikel diatom yang banyak tersebar di sungai. Walaupun herbiovora, tapi juga materi kering dan kecil dipermukaan pun (termasuk serangga) juga dimakannya. Tidak heran jika mudah ditemukan berenang dipermukaan sungai.

Capung merupakan fauna yang paling banyak ditemukan di sekitar sungai Surgi Mufti. Hal ini karena kondisi sungai yang tidak mengalir deras memberi kesempatan kepada capung meletakan telurnya di sungai tersebut. Capung Orthtrum sabina merupakan spesies yang paling banyak ditemukan. Menurut Jumar (2000) kisaran suhu yang efektif untuk serangga berkisar antara 25-45 ${ }^{\circ} \mathrm{C}$. Sedangkan kelembaban $76 \%$ dengan kondisi cuaca cerah. Kondisi ini mirip dengan kondisi di sekitar sungai Surgi Mufti dengan suhu sekitar $28-32{ }^{\circ} \mathrm{C}$ dan kelembaban udara antara 70 $85 \%$. Masih adanya beberapa pepohonan yang ada di sekitar tersebut dan bangunan sekitar sungai yang memberi sedikit naungan sehingga membantu suhu dan kelembaban tidak terlalu tinggi.

Dari jenis kupu-kupu, paling tidak ditemukan ada 8 spesies dari ordo lepidoptera ini. Jumlah individu tiap spesiesnya memang tidak banyak, hal ini kemungkinan juga karena daya jelajahnya yang relatif luas, sehingga tidak menetap di sekitar sungai Surgi Mufti. Ada beberapa tipe habitat lain di sekitar sungai yang juga disinggahi kupu-kupu, dimana habitat tersebut memiliki sedikit kesamaaan vegetasi.

Beberapa jenis herpetofauna hidup di sungai Surgi Mufti, yaitu dari jenis amfibi dan reptil. Secara keseluruhan tidak banyak spesies yang ditemukan, tapi bisa menjadi penting bagi ekosistem sungai tersebut. Bufo aster, Fajervarya cancrivora, dan Rana chalconota adalah Amfibi dari ordo Anura yang paling banyak ditemukan. Keberadaan mereka mengundang jenis ular Calloselasma rhodostoma (ular tanah) ada di sana. Karena fauna dari ordo Anura tersebut merupakan makanan mereka. Dalam rantai makanan, keterkaitan antar komponen biotik menjadi hal penting dalam stabilitas ekosistem.

Burung merupakan fauna yang mudah ditemukan di sekitar sungai Surgi Mufti. Menurut MacKinnon, et al (2010) burung termasuk fauna yang menempati sekitar rawa air tawar Kalimantan. Walau pun tidak sekaya hutan di rawa kering, tetapi adanya pohon tinggi misal pohon rambai (Soneratia sp.) yang tumbuh di bagian muara sungai Surgi Mufti, memberi tempat dan kehidupan bagi burung. Misal beberapa Orthotomus ruficeps yang bertengger di pohon tersebut. Pada saat lain, jenis dari raja udang (Alcedo meninting) pun terlihat ada di satu dahannya. Sedangkan jenis elang Haliastur indus, hanya terlihat lewat di sekitar sungai Surgi Mufti. Habitat mereka berada sekitar $800 \mathrm{~m}$, yaitu di mangrove Banua Anyar yang berada di tepian sungai Martapura. Ada juga jenis tumbuhan rendah seperti dari family Poacea yang banyak tumbuh di bagian zona amfibi. Tumbuhan ini lebih disukai spesies Lonchura fuscans (Bondol Kalimantan) yang menyukai makan biji-bijian dari poaceae tersebut.

\section{Keanekaragaman Fauna}

Walau pun kondisi sungai Surgi Mufti semakin memprihatinkan, tetapi masih memberi ruang bagi habitat beberapa hewan. Beberapa zona sungai mulai hilang, misal zona kering yang merupakan riparian sungai sudah hilang 
dibeberapa bagian karena bangunan rumah warga yang letaknya pas di sisi sungai. Bangunan tersebut bahkan juga masuk ke zona amfibi melewati batas siring yang dibangun dinas Kementerian Pekerjaan Umum. Kondisi ini jelas sekali merusak bahkan menghilangkan habitat di sungai tersebut.

Dari keanekaragaman berkategori sedang ini paling tidak dapat kita lihat bahwa:

1. Ada potensi menurunnya keaneragaman karena rusaknya lahan. Berakibat tergerusnya habitat secara perlahan. Indikasi juga bahwa keberadaan sungai Surgi Mufti terancam hilang. Hal ini dapat terlihat adanya badan sungai di bagian dalam yang mengecil di bawah $1 \mathrm{~m}$, bahkan hampir nol.

2. Keanekaragaman sedang ini berpotensi meningkat jika ada beberapa usaha restorasi sungai. Misal penanaman pohon untuk mengembalikan habitat dan usaha-usaha menyadarkan warga untuk menjaga sungai tersebut.

3. Dari beberapa kelompok fauna yang ditemui, terlihat adanya hubungan rantai makanan. Misal antara larva serangga, ikan, amfibi, reptil, dan burung, terjalin suatu rantai makanan dan aliran energi. Rantai tersebut akan semakin komplek jika kondisi habitat semakin membaik, tapi berpotensi semakin memburuk jika habitat semakin rusak. Berimbas juga pada warga sekitar. Hal ini diketahui dari laporan warga tentang adanya ular yang masuk ke dalam rumah. Hal ini kemungkinan karena rusaknya habitat mengganggu keberadaan kodok dan katak yang merupakan makanan bagi si ular.

4. Adanya layanan ekosistem yang masih berfungsi. Misal keberadaan ikan yang layak makan bagi warga. Tetapi dengan pencemaran, jenis-jenis ikan tidak banyak yang bisa ditemukan. Misal karena hilangnya pohon Soneratia sp. Yang pada akarnya tempat ikan bertelur. Usaha penanaman kembali yang bisa dilakukan warga akan mendorong kembalinya ikan hadir di sana.

\section{KESIMPULAN}

Ada 45 spesies yang ditemukan di sekitar sungai Surgi Mufti yang terdiri dari 12 jenis capung, 9 jenis herpetofauna, 9 jenis burung, 8 jenis kupu-kupu, dan 7 jenis ikan. Antar spesies tersebut menunjukan adanya rantai makanan sebagai satu bentuk bagaimana stabilitas/ keseimbangan diekosistem. Walau pun keanekaragaman secara keseluruhan menunjukan pada kategori tinggi namun secara termasuk dalam kategori sedang, yaitu antara $1 \leq \mathrm{H}^{\prime} \leq 3$. Kategori ini bisa berkurang bisa naik tergantung bagaimana perlakuan masyarakat terhadap sungai tersebut.

\section{REFERENSI}

Banjarmasin, K. K. S. K. (2012). Laporan studi environmental health risk assessment (EHRA) Kota Banjarmasin.

Jumar. 2000. Entomologi Pertanian. Jakarta: Rineka Cipta.

Khaliq, A. 2015. Analisis Sistem Pengolahan Air Limbah Pada Kelurahan Kelayan Luar Kawasan IPAL Pekapuran Raya PD PAL Kota Banjarmasin. Jurnal Poros Teknik, 7(1)

Kottelat, M., \& Whitten, T. 1996. Freshwater fishes of Western Indonesia and Sulawesi: additions and corrections. Hong Kong: Periplus Editions.

Pemko Banjarmasin. 2015. Data Pembangunan Kota Banjarmasin.

MacKinnon, J. R., Phililipps, K., \& Balen, S 2010. Burung-burung di Sumatera, Jawa, Bali dan Kalimantan: termasuk Sabah, Sarawak dan Brunei Darussalam. GEF Biodiversity Collections Project, Puslitbang Biologi-LIPI.

Magurran, A. E., \& McGaill, B. J. 2011. Biology Diversity, frontiers in measurement and assessment. New York: Oxford University Press.

Maryono, A. 2005. Eko-Hidraulik Pembangunan Sungai. Yogyakarta. Penerbit UGM.

Weber, M. and L.F. de Beaufort. 1922. The Fishes of The Indo-Australian Archipelago IV:374-76. Leiden : E.J. Brill. 